\title{
Providing adaptations for Special Education Mobile Learning
}

\author{
M.J. Rodríguez-Fórtiz*, A. Fernández-López, T. Ruiz-López, C. Rodríguez-Domínguez, M. Cabrera- \\ Cuevas and M.L. Rodríguez-Almendros
}

University of Granada. ETSIIT and CITIC-UGR Granada, Spain.

\begin{abstract}
The development of mobile technologies is opening new possibilities in the field of education, specifically when it involves people with special educational needs (SEN). Mobility gives freedom to carry out learning activities at any moment or place. However, given the variety in SEN, it is difficult to create educational contents that fit for everybody. Rather, it seems appropriate to incorporate adaptation mechanisms that take into account the user profile, context or progress to modify the learning activities and adjust interaction, contents or presentation to the user's needs. In this paper, an abstract architecture is presented to guide in the construction of mobile applications for SEN. It comprises five models: activities, user, evaluation, cooperation and authoring, with different adaptable features. To illustrate the proposal, the architecture has been implemented in two learning tools, Picaa and Sigueme, which have been successfully used by children with special needs.
\end{abstract}

Keywords: mobile learning, Special Education, Software Adaptations, User profiles

Received on 16 January 2014, accepted on 14 May 2014, published on 09 September 2014

Copyright (C) 2014 M.J. Rodríguez-Fórtiz et al., licensed to ICST. This is an open access article distributed under the terms of the Creative Commons Attribution licence (http://creativecommons.org/licenses/by/3.0/), which permits unlimited use, distribution and reproduction in any medium so long as the original work is properly cited.

doi: 10.4108 / fiee.1.1.e4

\section{Introduction}

Learning disabilities [1] are a disorder in one or more of the basic psychological processes that limit the development and use of social, academic and communicative abilities, including conditions such as perceptual disabilities, brain injury, minimal brain dysfunction, dyslexia, and aphasia. Besides these, there are other learning problems that are primarily the result of neuronal impairments, sensorial or motor disabilities, mental retardation or emotional disturbance [2]

The students with learning problems present difficulties in some of the following aspects [3]:

- Attention deficits.

- Perception deficits.

- Hear or Visual deficits.

- Memory deficits: hold and retrieve.

- Processing speed deficits.

- Comprehension-knowledge and language deficits.

- Reasoning and problem solving deficits.

"Corresponding author. Email:mjfortiz@ugr.es
- Basic reading skills and reading comprehension deficits.

- Limited language.

- Difficulties to thinking for themselves.

- Lack of social and communication skills.

- Lack of interest regarding educational contents.

- Difficulties in analysing, synthesizing, discriminating or abstracting contents and making generalizations.

- Difficulties to applying the acquired knowledge to other environments.

The learning problems vary between individuals from mild to severe. Their main effects are low performance in all intellectual tasks, isolation, frustration, anger, serious behavioural problem, problems with daily living task (solving problems, planning activities, communicating with others, etc.), diminution of confidence, feelings of failure, dependence from others...

Students with disabilities must have full access to schools and teachings, on the same basis as other students, participating equally in the learning experience. The use of technology enables flexible curriculum development, assisting students with or without disabilities and their educators. Most technologies used in schools do not 
enable educators to create accessible learning activities for class. They are static, their interface (presentation and interaction) and contents cannot be customizable or are not easy to use.

The goal of accessibility [4] is to remove barriers in the applications to allow its use by all the users, independently from their physic and cognitive characteristics. The universal design is defined as the design of products and environments to be usable by all people, to the greatest extent possible, without the need for adaptation or specialized design. [5]. The principles of the universal design are: equitable use, flexibility in use, simple and intuitive use, perceptible information, error tolerance, low physical effort, and size and space for approach and use.

UNESCO report [6] gives some key recommendations for the use of accessible ICT and universal design for providing inclusive education:

- Maximise use of accessibility features in currently available technologies used to access the curriculum contents with different software platforms.

- Facilitate students to 'self-accommodate' by learning the computer features that best suit their needs, making the adaptations that are necessary for each user profile.

- Monitor and exploit the potential of new developments and near-future technologies as a means of addressing current barriers: mobile learning, cloud-based solutions, touch screen, context aware devices, gesture interactive user interfaces and research into the use of game consoles for learning.

- Create an inclusive and positive attitude towards the use of technology for learning, by educators, parents and administrators.

- Train and support educators to have the necessary skills, attitudes and knowledge.

- Provision, training and on-going support required for effective accessible ICT usage is a 'team effort'.

- Consider students' needs from the earliest stages of curriculum development, reducing the need for costly and time consuming retrofitting (universal design).

- Include in national and regional policies the promotion of the accessible ICTs as a key tool for achieving Inclusive Education.

- The use of accessible ICTs needs to be an integrated part of a school's ICTs plan: What can ICT offer pupils and staff that cannot be offered just as well in other ways? How can ICT help pupils and educators to access a broad range of activities across the curriculum? How can ICT promote equal opportunities?

The satisfaction of general accessibility criteria could benefit to all users with or without special needs but a unique final design could not be useful for every kind of users [7]. For example, a predominantly textual design will be accessible for blind people but not for deaf users or people with cognitive disability, for whom a more visual design (using images and animations) is more suitable. Nielsen [8] also thinks that the dynamic adaptation of the user interface according to his/her own needs and characteristics is the best decision to overcome accessibility and usability barriers. With the same perspective, other authors [9] [10] propose new software approaches, including in lifecycle customized solutions, which give each user the same opportunities than others to use the computer.

Three factors are considered to perform adaptations:

- User profile: The behaviour, aspect and software functionality change depending on the user characteristics. If the adaptation is performed during the design process, the software is adaptable, but if the adaptation must be carried out at real time, the software is adaptive. Sometimes, software must fit the users, and then, rules based on previous user interaction and response must be specified using for example recommendation systems.

- User context: Position, time and other contextual information (weather, performed task, user health measurements, etc.) determine the contents and the way of user interaction for the application. For instance, this is the case of ambient intelligence systems.

- Software platform: Software should adapt its functionality and interface to improve the devices and software management. Different platform (PCs, smartphones, tablets, videogames consoles, etc) with different parameters as screen size, connections, memory, kind of interaction, etc. should also be available.

In this context, mobile technologies offer a great opportunity to overcome the barriers that exist between students with learning problems and commons tasks like communication, learning or socialization.

Usage of mobile devices provides to users four classes of help [11]: aid for carrying out functions in every-day activities, a means to communicate, support in the learning process and use as assistant.

A new educational paradigm arises from the application of mobile technologies in the classroom, mobile learning a booming paradigm based on mobile devices supported learning that provides autonomy and ubiquity and facilitates interactions between users thanks to devices' connectivity [12]. Besides, mobile learning has the following advantages [13]:

- Control and freedom to define tasks and relate activities.

- Mobile devices seem to give their users a very strong sense of control and ownership. 
- Communication between students, thus enabling collaborative activities.

- Fun devices.

- Learning-in-context.

- Continuity between different contexts.

This new technological-pedagogical model provides the opportunity to implement innovative ways to teach and learn, so our contribution is focused to the mobile learning for students with educational special needs.

The second section of this paper shows some related works with our proposal, which is presented in section 3 . Section 4 describes two applications based on the proposal and finally, section 5 ends with our conclusions.

\section{Related works}

Pictographic systems based technologies predominate in the field of ICT for Special Education. In this section, a review several representative tools will be show. The last version of all of them have been analysed at time of writing this paper. One of the greatest exponents of pictographic tools is BoardMaker from Mayer \& Johnson, widespread commercial software that uses a proprietary system called Picture Communication Symbols (PCS). This tool has the main limitation of not being oriented for mobile technology.

This manufacturer has developed other products in this sense as Flash Cards, Bingo PCS or PCS Memory, but all of them make use of a proprietary vocabulary of symbols and they allow little or any configuration. In this case the company has developed with other products different to augmentative communication systems but the proposals have been very limited in functionality and highly fragmented (a different product for each task).

Other manufacturers of authoring tool for PC oriented to the creation of communication systems, such as Sensory Software with The Grid 2 or TapToTalk have created templates viewers for mobile platforms like iOS (iPhone, iPhone and iPod touch) or Android. However, these viewers need to use the PC authoring tool to configure the contents.

Some companies have developed augmentative communication tools oriented to devices such as iPhone or iPad (Figure 1), such as Tobii Sono Flex, Proloquo2Go of AssistiveWare or Grace. These tools represent an advance over previous cited because they offer greater mobility and versatility by including customization capabilities independently on the device. Both systems make use of specific pictorial: Flex incorporates SymbolStix and Proloquo2Go VocaSpace. Again, although the proposals include new or interesting features not deep into other areas useful for special needs students and their tutors.

There are also very useful tools for students with profound and multiple learning difficulties focused mainly to improve the attention and cause-effect skills. Examples of these are Senswitcher or but the majority of them are not configurable and can be only used in PC, not in tablets. Two exceptions are FindMe and Autism iHelp.

Findme is a mobile application to help children to identify people or objects. It has several levels with increasing difficulty with the incorporation of more distractor elements. It allows three different types of adaptations: adjusting the difficulty level to the child's capabilities, selecting an image which will be used as a reward for completing an exercise, and recording a voice message to reinforce the learning process. Besides, it has a statistics module with some data about the time played, the number of completed activities, and the highest level reached by the user.

Autism iHelp is a set of mobile applications with different activities, including language concepts, sorting, colors, questions, same and different, opposites or shapes, among others. It has some options for adaptation in each activity, mainly to adjust the difficulty of the exercise, but it does not allow to modify the contents or the interaction mechanism. The applications have a progress report to indicate the percentage of completion of the exercise.
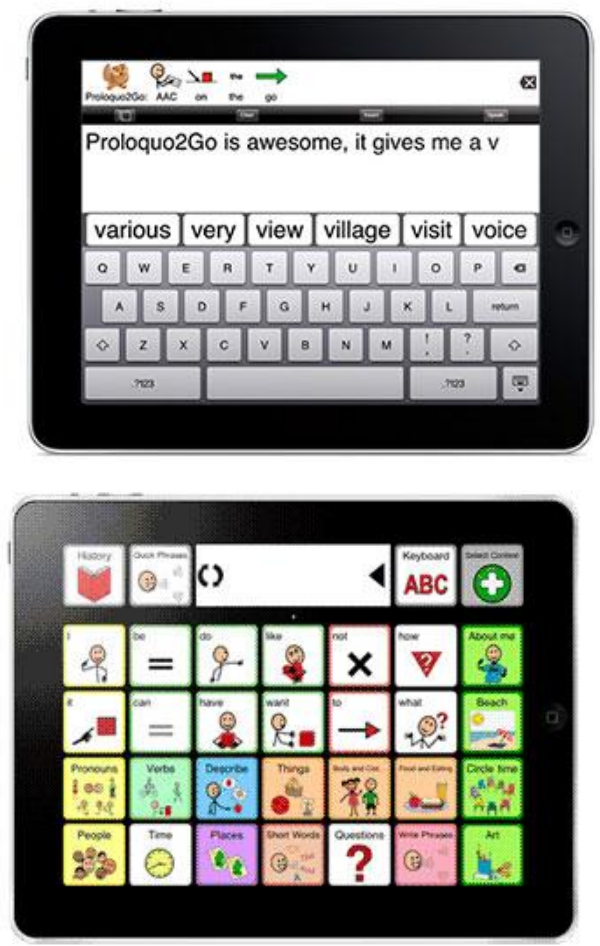

Figure 1. Mobile tools targeted for Special Needs.

All the tools mentioned above have proven useful and widely used by students with special needs. Our research group has several years of experience (since 2004) working in several projects with professionals of Special Education Schools of Spain who used these tools. In the interviews maintained, some of these professionals demanded take a step forward, moving into more complete applications and extending its functionality by adding new capabilities to be used in a learning context, thanks to technological advances. 
The learning activities must be programed to each student with a particular order and duration, selecting objectives and contents to be used and evaluated, and creating or using the material resources and spaces more appropriated [16]. Specifically, learning activities must help to work on other issues different to AAC (Augmentative and Alternative Communication) as memory stimulation (hearing, visual, short-term, work...), hand-eye coordination, vocabulary, attention, perception, cause-effect relationships, priority, examination of assumptions, reading, writing, syntax, calculations or strategies for the resolution of problems, association of ideas, sorting sequences of steps, etc.

Regarding this last point, the application stores are full of apps dedicated to developing all these skills (see Figure 2). Mobile apps are proving an excellent way to provide educational content, both in terms of popularity and availability [17]:

- About $80 \%$ of the payment applications are among the 10 most downloaded are aimed at children.

- In 2009 almost $47 \%$ of the top selling apps were aimed at preschool and early primary education cycle. This number has been increasing to reach $75 \%$.

- The percentage of apps aimed at children has increased in every age and in turn, decreases in adults.

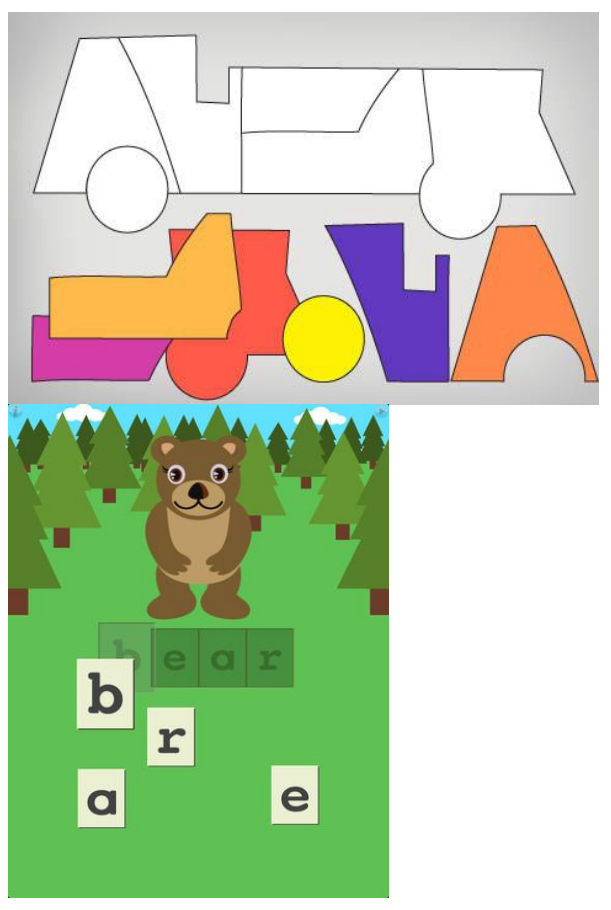

Figure 2. iPads apps: ShapeBuilder and FirstWords.

There are various computer-based interventions to facilitate the progress of people with cognitive impairments in communication, language and learning. In
[18] and [19] a lot of of them have been compared focusing in autism, analysing the validity of the studies and the confidence with the results. The majority of these tools are based on the use of textual and graphical representations (specific pictograms, photos or pictures) that the child must recognize to begin the intervention. They are useful for performing only one or very few learning activities. They are not targeted for students with special needs and have no customization options, greatly limiting its applicability to these users. Besides, the big majority of the studies tested less than 5 users.

Nevertheless, it would be interesting that there were tools that combine the features present in assistive technologies with educational content activities, adding new functionality to help them at class. The professionals of special education that we have queried proposed to include the next specific requirements for a new educational application: learning contents adaptation, user adaptation capabilities, portability, group work and evaluation. The application must include an authoring tool to make those adaptations and help in the preparation of the materials.

\section{Adaptive Mobile Learning Proposal}

Our aim is to design an architecture to support mobile learning system for students with educational special needs. In this regard, our main goals are:

- Giving the possibility of using applications with learning activities in different environments and places.

- Providing educators and professionals a means to take part in the educational process sharing devices and applications that allow their communication.

- Increasing the communication between partners and allowing the possibility of performing collaborative learning activities, helping the integration of the user in their social environment.

- Providing usable tools for the educators, which make their daily work easy.

- Helping the educator to evaluate students' progress and make decisions based on them to improve and fit the learning activities.

- Creating flexible tools, which allow the educators adapt the curriculum development for their students and achieve inclusive education.

- Promoting a contextualized learning to the environment, student and activity at each moment.

The use of mobile devices contributes to guarantee some of these goals in education because their main characteristics are: mobility or portability, touch screen, interaction through motion, accessibility functions and connectivity.

At the educational level, our proposal of an adaptive mobile learning system must collect some of the properties from the next learning perspectives [16] [17]: 
- Mobile: Contents must be provided from mobile tools that offer autonomy in the learning process, help performing activities everywhere and facilitate the implication of families and professionals in the education.

- Conductual: Learning is based on the representation of problems, whose solution is directed by elements that provide a value for the solution and a reinforcement of the knowledge with the feedback.

- Constructivism: The student creates his/her own knowledge based on new ideas and previous knowledge.

- Situational, contextual: Similar to constructivism but the scenarios are not simulated but real. The ubiquity of the user provides context information that can be used in the learning.

- Cooperative: Interaction mechanisms are provided to facilitate the tasks coordination and the communication between students and educators.

- Informal: The knowledge is acquired in a free environment, out of class but embedded in the particular space and circumstances of each student.

- Assisted: The main goal of the technology is assisting students and educator to provide resources to control, plan and evaluate activities and tasks.

- Adaptable: Educators must define a learning plan that allows designing flexible activities that can be easily adaptable to the learning needs and characteristics of each student.

Besides, taking into account the goals of our proposal, the following aspects must be defined for the adaptive mobile learning system framework(Figure 3):

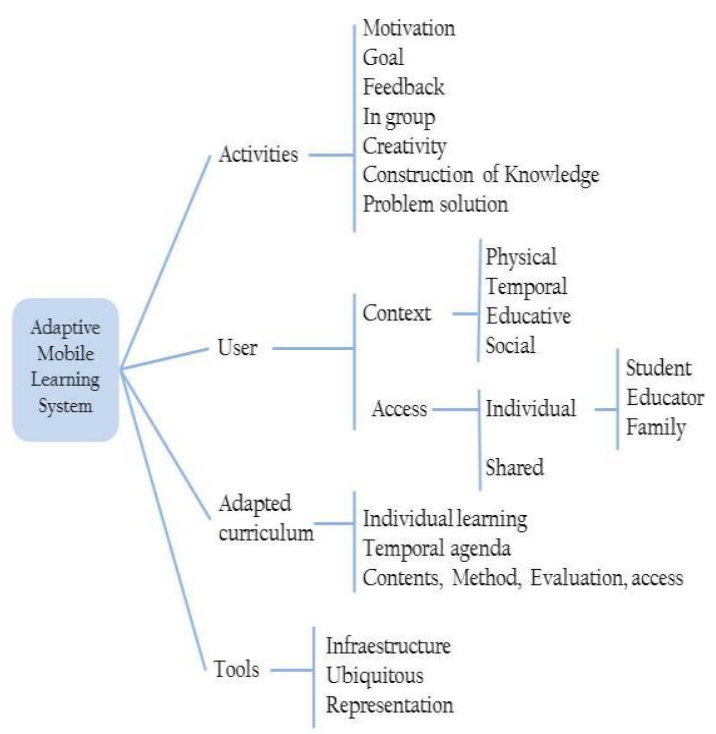

Figure 3. Basic aspects of the adaptive mobile learning

- Activities: They are the base of the learning process. Their properties take into account the conductual learning perspective, including for that: motivation, goals, feedback, multimedia elements, etc. The way of performing cooperative activities in group must also be considered. From the constructivism, contextual and informal perspectives, activities should be carried out in real scenarios and free environments closed to the students. This implies that the properties of each activity have to be defined considering the context of use and the needs, capabilities and preferences of the users.

- User: In order to offer the students adapted learning experiences, their physical, temporal, educative and social context must be considered. Their way to access the information, preferences of representation of information, way of interaction, etc. must be specified in access user profiles.

- Adapted curriculum: A learning system with quality must support a customized teaching fitting to adapted curriculums for students with special educational needs using an authoring tool. The use of the learning system must be assisted by the educator, including mechanisms to evaluate the user progress and to know if the system is useful for each student or if it needs to be adapted again to fit better the user.

- Tools: ICTs must improve the representation, interaction and user experience. Besides, to support the cooperative and mobile learning perspectives, the use of a distributed platform helps to increase the collaboration, mobility and ubiquity of the learning.

To implement the proposal, an architecture will be defined considering all the previous perspectives and aspects.

\subsection{Architecture}

The architecture consists of five models that will be described below: activities model, user model, cooperative interaction model and evaluation model. Architecture also includes an authoring tool to instance and configure each model (Figure 4). The correspondence between activities and user models and the basic activities and user aspects of the framework is direct. The other models have been created to separate concerns and facilitate the design and implementation of the proposal. Cooperative interaction model allows defining specific properties from the cooperative activities and tools to support the collaboration. The authoring tool model defines the mechanisms for customization considered in the adapted curriculum aspect. Finally, the evaluation is a specific requirement of the adapted curriculum and must be performed before the modification of the user profiles and activities using an authoring tool. The evaluation model has been separated from the authoring tool because its specific functionality.

Each model will be described in the next subsections. The customizable aspects of each one have been obtained from the literacy and from suggestions of special 
education professionals collaborators, during the developing of the projects.

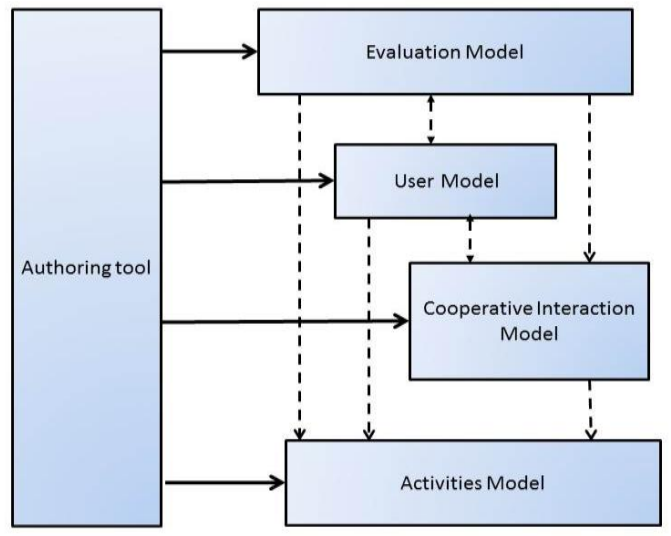

Figure 4. Architecture of the proposal

\section{Activities Model}

The learning system is conceived to be used by educators to create activities or exercises with different contents. Contents must be provided in different formats: audio, video, sound, text, pictures, pictograms, photos, sign language, etc. They must proceed from different sources and vocabularies. Sounds could be also recorded or synthesized using a text-to-speech (TTS) engine.The goal of each activity is achieving specific educative goals, helping to develop and improve capabilities in the students. The activities performed by the students in the school can be embedded in games containing educative contents. Students enjoy playing without noticing that they are learning concepts and acquiring socio-affective abilities. Each activity is characterized by several aspects that can by configurable (Table 1).

Table 1. Customizable aspects in the activities

\begin{tabular}{ll}
\hline Aspect & Value \\
\hline Kind of activity & $\begin{array}{l}\text { Used to learn specific concepts or } \\
\text { abilities }\end{array}$ \\
\hline Goals & $\begin{array}{l}\text { Aim of the activity, dynamic and } \\
\text { based on the students possibilities }\end{array}$ \\
\hline Contents & $\begin{array}{l}\text { Multimedia elements: pictures, text, } \\
\text { photo, video, audio, .. }\end{array}$ \\
\hline Presentation & $\begin{array}{l}\text { Configuration of colors, } \\
\text { backgrounds, sizes and distribution } \\
\text { of the contents }\end{array}$ \\
\hline Help, clues & $\begin{array}{l}\text { To make easy the learning when the } \\
\text { students have several fails or time is } \\
\text { passing without hits }\end{array}$ \\
\hline Level & $\begin{array}{l}\text { Difficulty level based on user } \\
\text { profile or previous interaction }\end{array}$ \\
\hline Reinforcement & $\begin{array}{l}\text { Rewards or penalties depending on } \\
\text { the successes or fails }\end{array}$ \\
\hline Times & $\begin{array}{l}\text { Time to complete the activity, time } \\
\text { attending or absent }\end{array}$ \\
\hline Feedback & $\begin{array}{l}\text { Accounting results of the interaction } \\
\text { for evaluation }\end{array}$ \\
\hline
\end{tabular}

\section{User model}

Students with educative special needs present a wide functional diversity. Each one could require a specific adaptation because his/her needs, capabilities, motivations and interaction way can be unique. The user model defines the characteristics of each user in order to adapt the activities to him/her. One important characteristic is the user interaction because his/her mobility, the use of special devices for accessing to the computer and the format of the contents chosen must be taken into account. For example, in the case of a pupil that can not use his/her hands to touch the screen or manage a mouse, he could interact with hi/hers voice, eye movement or using special switches with different parts of his/her body. To facilitate the access and selection of contents, the interface of the tool should also be adapted to the user.

Table 2 shows some adaptations that can be selected depending on the user limitations and the activity.

Table 2. Customizable aspects in the activities

\begin{tabular}{ll}
\hline Limitation & Adaptations \\
\hline Visual & $\begin{array}{l}\text { Colours, magnification, contrast, } \\
\text { text to graphic, voice synthesis, touch } \\
\text { interaction or use of scanning or } \\
\text { voice. }\end{array}$ \\
\hline Auditive & $\begin{array}{l}\text { Subtitles, alert graphics or text, sign } \\
\text { language, adapted vocabulary }\end{array}$ \\
\hline Cognitive & $\begin{array}{l}\text { Interface and vocabulary simplicity, } \\
\text { no distractors, prioritization of } \\
\text { graphics, guided use, hints and tips, } \\
\text { difficulty levels. }\end{array}$ \\
\hline Motor & $\begin{array}{l}\text { Interaction using scanning } \\
\text { combining with voice or using of } \\
\text { specific peripherals. }\end{array}$ \\
\hline
\end{tabular}

As part of the user profile, it is useful the definition of an agenda to organize activities during the day and in different days of the week. The agenda allows a temporal organization of the activities to each user.

\section{Cooperative interaction model}

Cooperative learning has been frequently seen as a stimulus for cognitive, social and emotional development because of its ability to stimulate social interaction and learning between members of a group [20].

In the case of students with special needs is helpful to promote socialization and training of forms of interaction with others. In this context, the use of mobile devices to develop learning systems offers possibilities that are not available with traditional methods. Mobile devices represent a new opportunity for collaborative learning of students [121], thanks to its inherent characteristics: portability, mobility, connectivity, accessibility, and adaptability [22].

Cooperative activities help to increase the positive interdependence and to offer models to be imitated. In this sense, awareness is used to show the interaction of the 
partners and the state of the activity in course: informing about scores, who has the turn, times, successes and failures, achieving of goals, etc. For a cooperative activity, the multimedia used in its contents and the interaction way can be different for each user who works in group to ensure the adaptation to the user profiles. Besides, several aspects of the cooperation can be customized (Table 3).

Table 3. Customizable aspects in the cooperative activities

\begin{tabular}{ll}
\hline Aspect & Value \\
\hline $\begin{array}{l}\text { Number of } \\
\text { users }\end{array}$ & From 2 to n \\
\hline Orderly turn & $\begin{array}{l}\text { Fixed or variable, with time } \\
\text { assigned or not }\end{array}$ \\
\hline Goals & $\begin{array}{l}\text { Individual or collective } \\
\text { goals }\end{array}$ \\
\hline Score & $\begin{array}{l}\text { Individual and collective } \\
\text { score, based in the achieving } \\
\text { of goals }\end{array}$ \\
\hline Awareness & Contextual information \\
\hline
\end{tabular}

\section{Evaluation model}

The application must help the educator to evaluate the students, their participation in the activities (scores, times, etc.) and the progress, comparing different work sessions and students.

The evaluations results can be used to make decisions about the need to modify some aspects of the activities to better fit them to a specific student. These modifications try to avoid his/her boredom, frustration, abandon or nervous crisis.

Sometimes, the educator can perform the activities as a student to guide other students in the learning process teaching how to perform the activities.

\section{Authoring tool}

It is essential for the success of the learning system the inclusion of an authoring tool that provides educators with capabilities to customize the models described above. The customization can be performed taking into account the work methodology in class, the competences and contents to be taught, the students' profile and the context (physical, temporal, educative, social...).

If the authoring tool is integrated in the same device that the user tool, and this device is mobile, the learning system increases its potential because educators can customize the activities and the user profile at any time and place. The adaptation process is immediate and the system is more sensitive to the context.

The development of applications based in this architecture follows a user-centered lifecycle. Educators and students must take part during the life of the project to provide functional and non-functional requirements and also test them. Besides, it should be driven by models (MDA) to describe models for specific platforms from the specification, getting automatic transformations.

\section{Picaa and Sigueme}

Based on our design proposal, we have developed two mobile learning systems for students with cognitive impairments that can also be useful for students with sensorial and motor disabilities due to their capability for being adaptable to the user characteristics.

The first one is Picaa (www.picaa.es), implemented for iOS devices (iPhone, iPad and iPod touch). Picaa is an authoring tool to design and personalize learning activities, adapting their contents, user interface and interaction way quickly and easily, on the device itself, without the need for long or complicated operations.

The authoring tool is integrated in the same app that includes the activities for users. To achieve this, it has two modalities depending on the user's role:

- Educators have access to all application modules, including capabilities of activities personalization and user profiles definition.

- Students only interact with those activities that educators have designed for them.

Picaa has been designed following the guidelines and requirements established by educators and field experts consulted, based on this new tool approach proposed in the previous section. Its main features are detailed below.

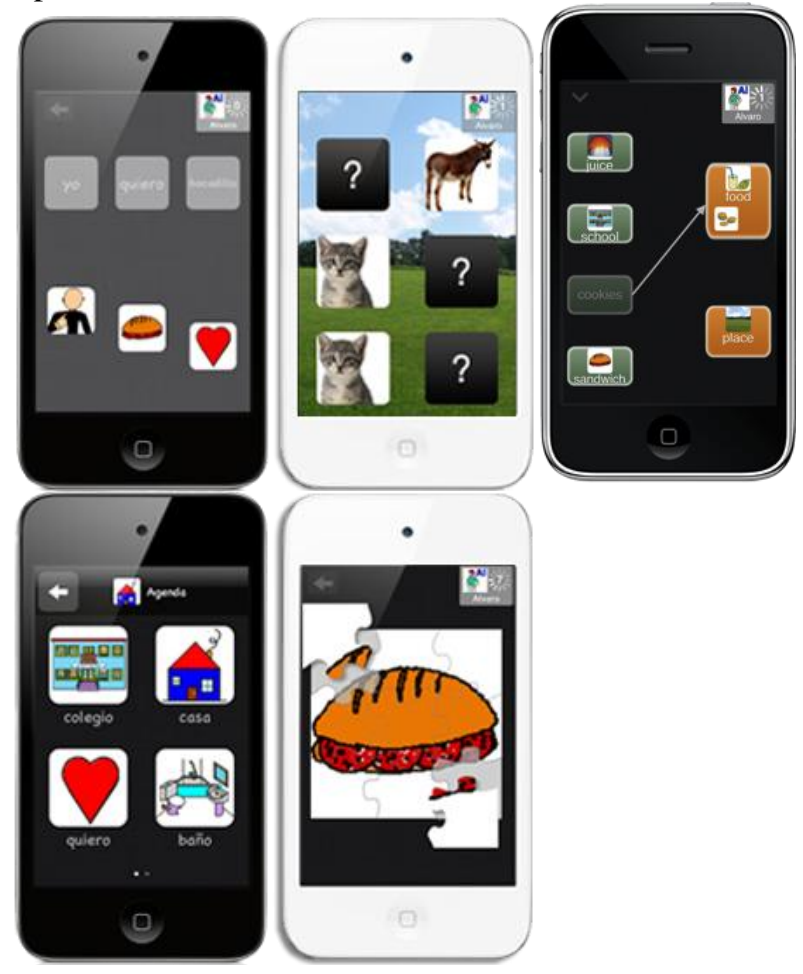

Figure 5. Picaa activities 
Picaa incorporates 5 types of activities (Figure 5) that are intended to cover some of the main tasks of learning:

- Association: There are two sets of elements so that the student must indicate the relationship between them. Several variants are contemplated: One to one: The set origin and destination all have the same number of elements so that each element of the original group element corresponds to a destination; Multiple: Origin and destination sets can have different numbers of elements; Identification: One set, origin or destination, has a single element to which they should associate the elements of another set that fulfills a certain property.

This activity is the basis to make lotus, memory exercises, calculation and discrimination.

- Puzzle: It presents an image decomposed into pieces of a puzzle that students should be ordered. Educators can configure the puzzle pattern, management of parts and the image on which to base the puzzle.

- Exploration: This activity is intended to enable students to learn concepts by navigating through a hypermedia system. This type of activity can be used to create simple communicators and agendas, showing an initial set of elements related to any issue so that selecting each of them new elements or reinforcing information (for example, an animated video) are shown. It can also serve for the student builds a story as browsing the hypermedia system, observing and selecting images, hearing sounds, showing animations and moving to other pages.

- Sorting: In this type of activity a set of elements is shown so that the user has to establish the correct sequence (for example, order a sentence). It allows the definition of distracting elements, ie elements that are not part of the sequence.

- Memory: This activity allows creating sets of memory (memory-match) with cards that are hidden initially and turn around every time the user pressed. The goal is to match the same images. There is also a mode where user must match each image with its associated text.

The authoring tool of Picaa (Figure 6) enables educators to create and manage a collection of activities and by means of templates, they can select a type of exercise and determine some of its features: the number of components or concepts to be taught, screen composition, multimedia used to represent the components, etc.

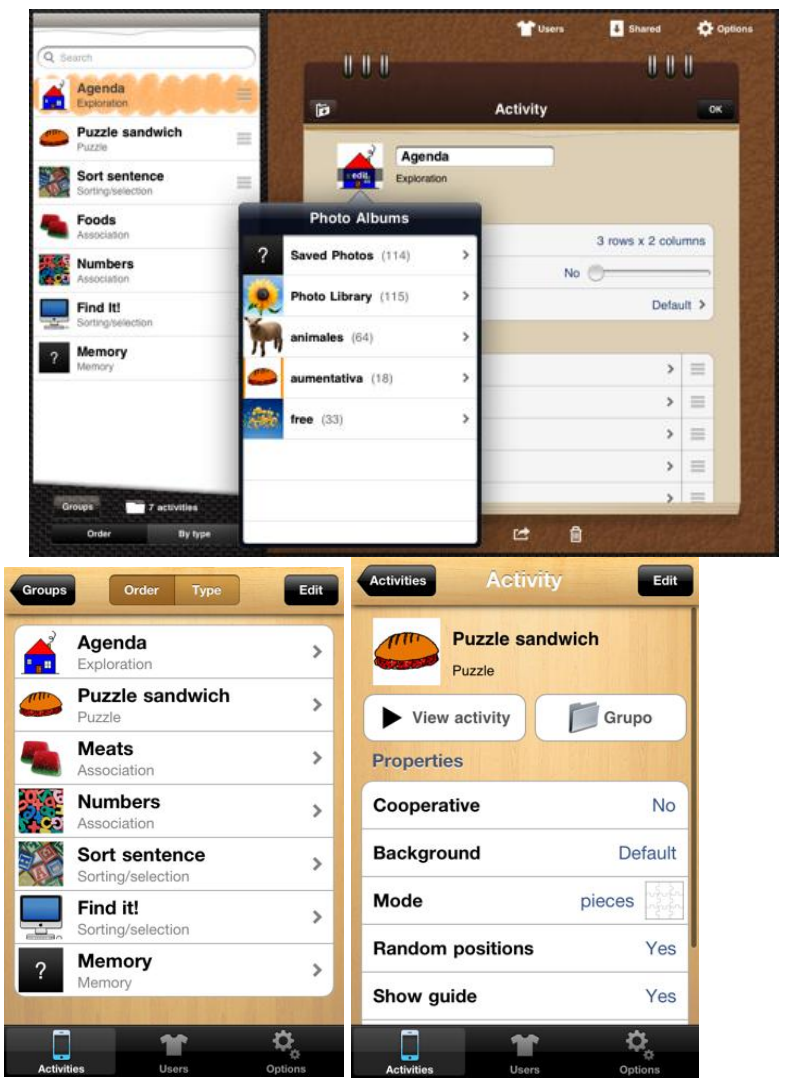

Figure 6. Collection of activities and an example of activity specification on iPad (left), and iPhone/iPod touch (middle and right).

Sigueme (www.proyectosigueme.com) is the second application implemented for iOS and Android tablets. It is also available for PC (Windows and Linux).

The goal of SIGUEME is teaching skills to enhance the development of the perceptive-visual process and cognitive-visual process in people with low-functioning and cognitive disability. Significant and comprehensive associations between visual elements as representations of the reality, together the acquisition of their verbal labels, can be achieved with this tool.

The software has been developed in six phases with activities, which range from the capture of the visual attention to the recognition of concepts using pictograms. The phases are:

- Attention: visual attention to basal visual stimuli (Figure 7). It involves 4 groups of activities presenting animations, path tracing and composition and decomposition of objects, among others.

- Video: trains visual attention to moving images in 3D realistic video sequences. Different concepts from habitual contexts of the student are presented during this and the subsequent phases in order to gain their meaning with an increasing level of abstraction. The videos show the concepts and associated objects to their functionality. 


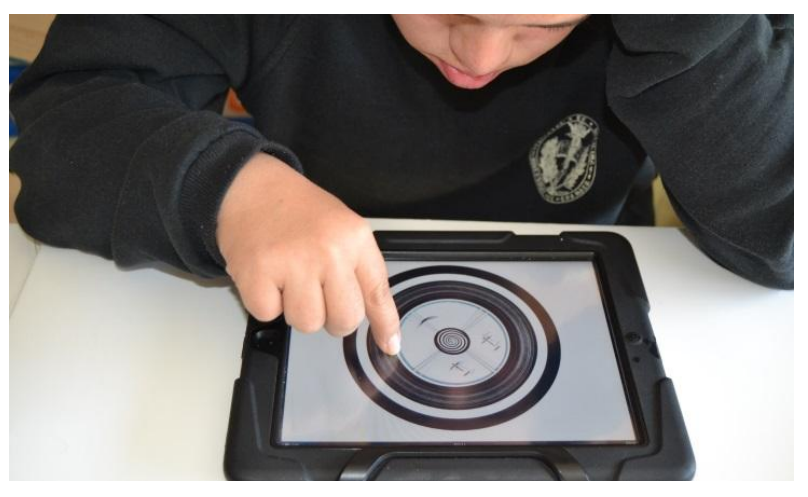

Figure 7. Visual attention in Sigueme

- Image: abstraction is increased from the previous phase by presenting same concepts using 2D photographs that are animated with simple movements (Figure 8). Four simple activities are proposed in order the child to recognize different concepts: backgrounds for images, video reinforcement, alignment of images, and contrast between images.

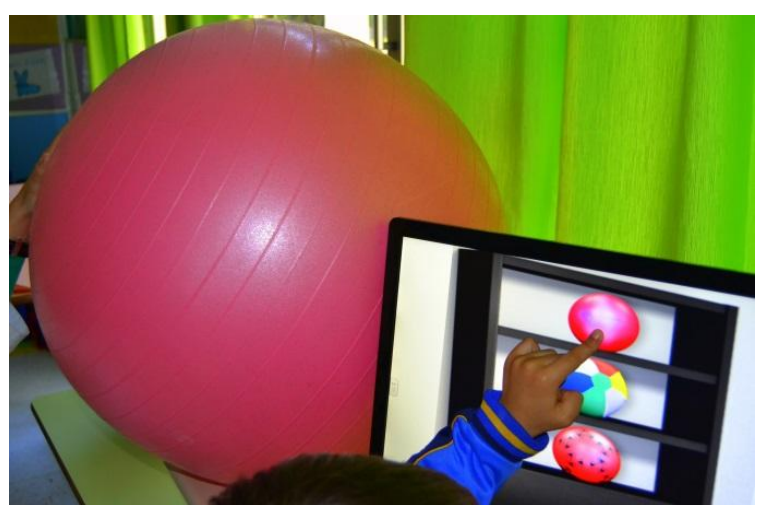

Figure 8. Visual attention to photos, pictures and pictograms (touch screen)

- Pictures: addresses the equivalence between a concept presented as a photograph, as a picture and as a gray scale silhouette; thus, the child is able to generalize the meaning of a concept besides its representation. The verbal label and the sign language gesture are also associated to the presentation of the concept in order to have a complete communication.

- Pictograms: recognition of pictograms through the use of different activities: exploring environments, making pairs, and look and point.

- Games: different activities are proposed to categorize representations of objects. The activities are storing objects into containers or classifying them. Images can be classified according to certain criterions: color, shapes, functionality, etc.

Both applications provide an authoring tool for the educators to design activities, configure the user profile,

and making the evaluation of the use in the same device used by the students. Picaa also allows configuring activities to support the cooperative use and provides an individual agenda of activities for each user. Figure 9 shows part of the authoring tool for the configuration of one activity of the Attention phase (in Spanish).

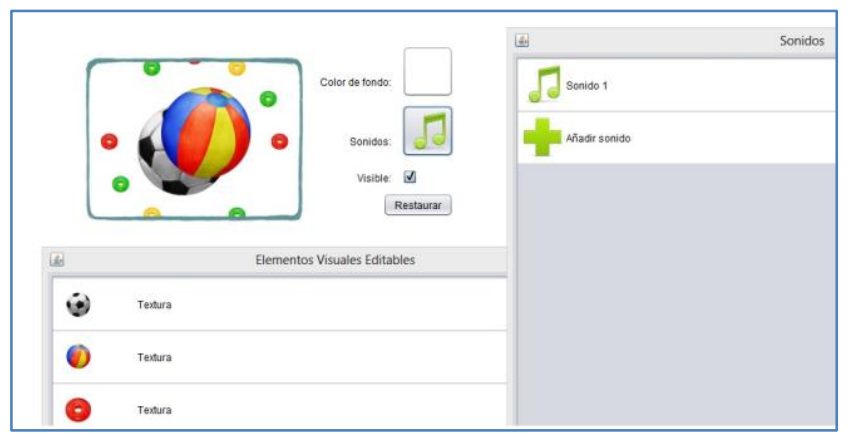

Figure 9. Configuration of an activity with the authoring tool of Sigueme

Examples of a different specific activity models for each application are shown in table 4 below.

Table 4. Customizable aspects in Picaa and Sigueme activities.

\begin{tabular}{|c|c|c|}
\hline Aspect & Picaa & Sigueme \\
\hline $\begin{array}{l}\text { Kind of } \\
\text { activity }\end{array}$ & Puzzle & Contrast \\
\hline Goals & $\begin{array}{l}\text { Place all the pieces } \\
\text { in the correct } \\
\text { position }\end{array}$ & $\begin{array}{l}\text { Recognize and } \\
\text { discriminate photos }\end{array}$ \\
\hline Contents & Image: photo, draw & $\begin{array}{l}\text { Photos, sounds, } \\
\text { text, video }\end{array}$ \\
\hline Presentation & $\begin{array}{l}\text { Shape of pieces, } \\
\text { sound, image, } \\
\text { background }\end{array}$ & $\begin{array}{l}\text { Photos in several } \\
\text { positions, text, } \\
\text { sounds }\end{array}$ \\
\hline Help, clues & $\begin{array}{l}\text { Correct piece or } \\
\text { position are } \\
\text { higlights or piece } \\
\text { are moved } \\
\text { automatically }\end{array}$ & $\begin{array}{l}\text { Correct photo is } \\
\text { selected } \\
\text { automatically }\end{array}$ \\
\hline Level & $\begin{array}{l}\text { Different shapes or } \\
\text { number of pieces, } \\
\text { background images }\end{array}$ & $\begin{array}{l}\text { Different number of } \\
\text { photos and } \\
\text { interaction ways: } \\
\text { automatic, touch } \\
\text { anywhere, touch in } \\
\text { correct position, } \\
\text { drag and drop. }\end{array}$ \\
\hline Reinforcement & Sound, score & $\begin{array}{l}\text { Movement of } \\
\text { photos, sound and } \\
\text { video }\end{array}$ \\
\hline Times & $\begin{array}{l}\text { Time in } \\
\text { completing the } \\
\text { activity }\end{array}$ & $\begin{array}{l}\text { Time in completing } \\
\text { the activity, Time } \\
\text { attending or absent }\end{array}$ \\
\hline Feedback & $\begin{array}{l}\text { Score with number } \\
\text { of successes } \\
\text { (pieces in correct } \\
\text { position) }\end{array}$ & $\begin{array}{l}\text { Information about } \\
\text { times and number } \\
\text { of successes and } \\
\text { fails. }\end{array}$ \\
\hline
\end{tabular}


Respect to the user model adaptations, Picaa and Sigueme allow changing colours, voice and sounds, images, video, text, sign language videos. At the cognitive level, they provide interface and vocabulary simplicity, prioritizing the use of graphics and with a guided use and several difficulty levels, with hints and tips. Different motor skills are considered allowing the user to interact touching the screen in a specific position or not, or requiring drag and drop. In the case of Sigueme, the use of a PC allows the interaction using the mouse or other specific peripherals as switches.

In order to illustrate the adaptation, activities for two different students using Picaa and Sigueme will be described. The first user is a child with low-funcioning, with auditory and attention difficulties. The second one has cognitive difficulties but a highest level than the first one, can read and recognizes pictograms. In their curriculum, the learning about mammals is included. Their teacher is going to use Picaa and Sigueme as alternative tools to teach about mammals. First of all, the teacher creates their user profile in each tool. Then, the activities are designed and customized for them.

In the case of Picaa, the puzzle activity has been selected to work with the representation of a mammal, specifically the photograph of a cow. For the first user, the puzzle has 5 pieces, and a background guide is shown to help with the position and shape of the pieces. Clues to move the pieces are also provided (Figure 10). The last user will work with the same photo, but a 35 pieces puzzle, without any guide or clues (Figure 11).

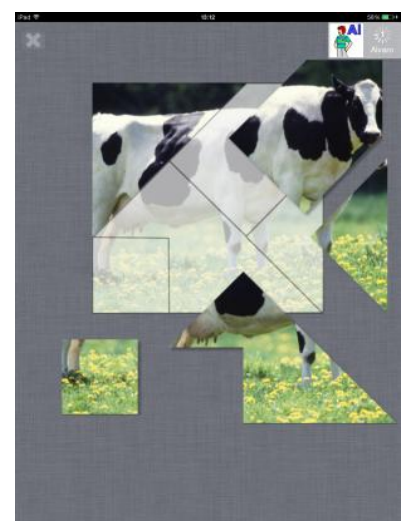

Figure 10. Picaa puzzle 5 pieces with aids

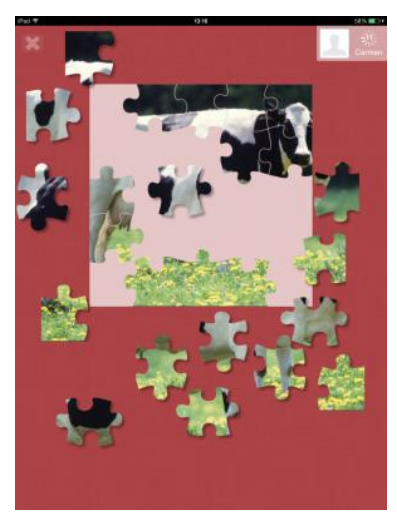

Figure 11. Picaa puzzle without aids
Respect to Sigueme, the first user has worked in the Pictures phase but only with the photo of the cow (Figure 12). The second one has worked also in the Pictogram phase associating pictograms and performing activities of making pairs, and look and point (Figure 13).

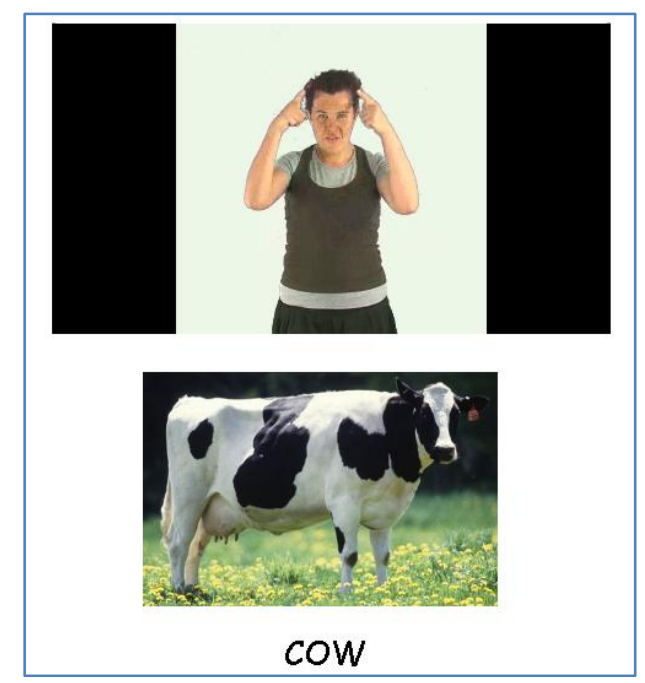

Figure 12. Sigueme Pictures phase, cow photo
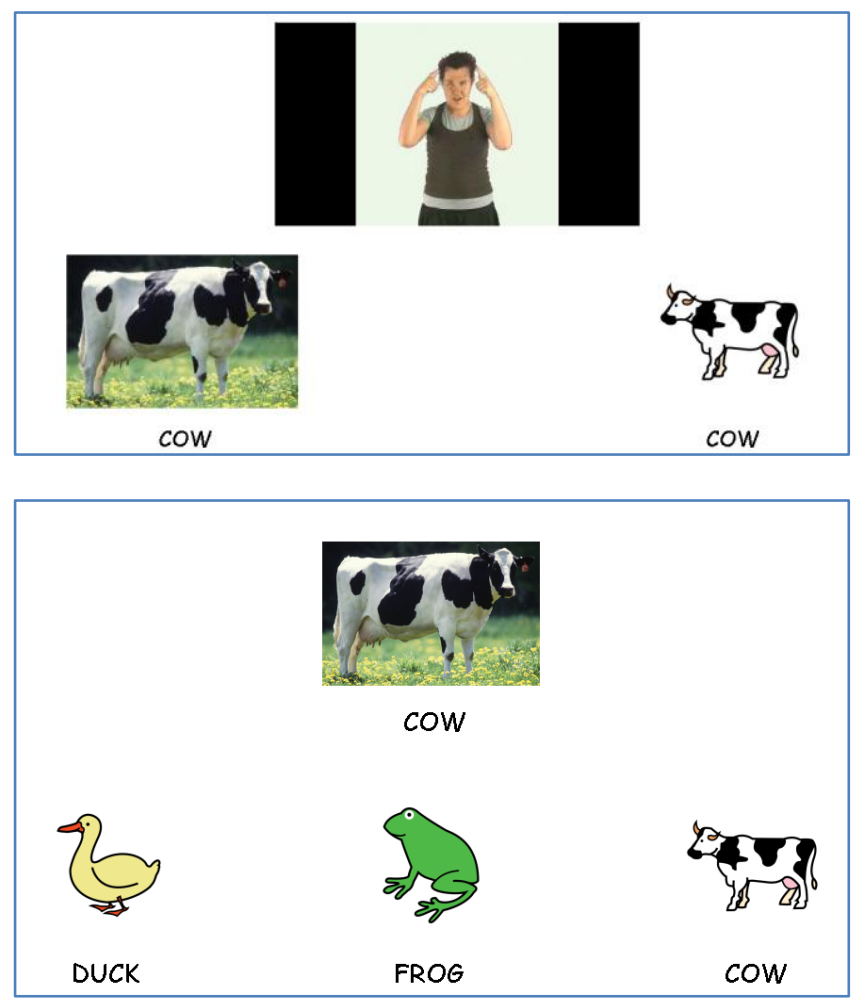

Figure 13. Sigueme Pictogram phase, making pairs activity (up) and look and point activity (bottom). 
Table 5 shows the cooperative interaction model of Picaa. One or more devices can be used to performing the activities in group.

Table 5. Cooperative interaction model in Picaa

\begin{tabular}{ll}
\hline $\begin{array}{l}\text { Number of } \\
\text { users }\end{array}$ & $2-4$ \\
\hline Orderly turn & $\begin{array}{l}\text { Fixed, created by the educator. } \\
\text { Dynamic, depending on the devices } \\
\text { that can be connected because are } \\
\text { close }\end{array}$ \\
\hline Goals & Ending the activities \\
\hline Score & Individual and collective scores \\
\hline Awareness & $\begin{array}{l}\text { User in turn, visualization of the } \\
\text { selections of other users when } \\
\text { different devices are used, } \\
\text { reinforcement from the result of the } \\
\text { interactions of the users in the } \\
\text { activities, changes in scores. }\end{array}$ \\
\hline
\end{tabular}

The use of digital whiteboards connected to the devices allows the visualization of the activities for several students at the same time. Then, although Sigueme does not implement the cooperative interaction model to support the configuration of activities for be performed in group because the low cognitive level of the end users, it can also be used in cooperative way guided by the educator using the original device or a digital whiteboard.

The evaluation model in Picaa collects individual and group scores and time in performing each activity. Sigueme also evaluates time of the user attending and being distracted. The number of successes and failures in each activity are also measured. Sigueme allows to compare the results between several sessions of different or equal activities for a user.

In order to test the benefits of the applications for educators and students, two pilot studies have been performed.

Picaa was tested during 6 months in 2012 [23] with 39 students with special education needs (autism, Down syndrome, brain palsy, and others) from 14 schools of Spain. Twenty six educators participated designing adapted learning activities as part of the educational curriculum of the students. The study was preexperimental with pre- and post- test about specific educative skills. The results of the study demonstrated that after using Picaa the students improved their levels in the basic competences of the Spanish educative curriculum: maths, language, social, personal, autonomy, and knowledge and interaction with the physical world. Another interesting result was that educators considered that Picaa is easy to use and increase the stimulation of the students. The educators evaluated Picaa as a useful and usable tool in their daily work in class.

In the test of Sigueme in 2013 [24] 78 students with cognitive impairment and low level of functioning participated. They came from 18 schools of Spain. Their teachers (51) also participated in the study using Sigueme during 25 sessions with their students and evaluating the tools benefits and utilities. This was also a preexperimental study with control group (same characteristics that experimental group but no using Sigume), using pre and post test for the children about cognitive, behavioural and motor skills. The results proved that Sigueme contributes to get and maintain the attention of the students, to get the cause-effect contingence and to improve their behaviour, their motor skills touching the screen and the linguistic comprehension. Sigueme helps to recognize different representations (photo, picture, pictogram, video and text) of real objects too. The study also demonstrated that the tool is useful for the educators because they did not know any similar tool, incremental and adaptive to the user preferences and specific learning needs.

\section{Conclusions}

ICTs are useful tools to help the acquisition of several cognitive and educative skills. In the case of students with intellectual disabilities these tools must be customizable to adapt the user profiles, educative needs, work rhythm, interests, capabilities and abilities. A framework and an architecture have been proposed to support mobile learning system with these objectives for students with educational special needs. Two tools, Picaa and Sigueme, have been developed following these framework and architecture, describing in this paper their main characteristics. Both of them implement the authoring tool model and also the user and activities model providing different kind of activities. Picaa implements the cooperative interaction model but not Sigueme because the low-functioning of their final users. Our tools have been tested with real users and a summary of the positive results of these tests has been presented. The cooperative use of Picaa is been tested at this moment and its evaluation model is being implemented. Our group is also working in new tools for special education using the proposal but improving it to include the modelling of the use of sensors to get user context information to be used in the activities performing and in the evaluation.

\section{Acknowledgements.}

This work has been supported by Orange Foundation (Sigueme) and MYCIN minister from Spanish government, TIN200805995 (Picaa). In the design and evaluation of the presented tools several Spanish shools have participated. We want to thanks their staff their effort and illusion. 


\section{References}

[1] Kavale, K.A. and Forness, S.R. (2000). What definitions of learning disability say and don't say. Journal of Learning Disabilities 33(3): 239 -256.

[2] IDEA. Identification of Specific Learning Disabilities. Office of Special Education and Rehabilitative Services (OSERS) in the U.S. Department of Education. (2006). Available in: http://idea.ed.gov. (accessing data: 27/04/2014)

[3] McGrew, K.S. and Woodcock, R.W. (2001). WoodcockJohnson III Technical manual. (Itasca, IL: Riverside Publishing).

[4] Ergonomics of human-system interaction - Part 171: guidance on software accessibility. Available in: http://www.iso.org/iso/

iso_catalogue/catalogue_ics/catalogue_detail_ics.htm?csn umber $=39080$ (accessing data: 27/04/2014)

[5] Connell, B, Jones, M, Mace, R, Mueller, J, Mullick, A, Ostroff, E, Sanford, J, Steinfeld, E, Story, M, \& Vanderheiden, G (1997). The principles of universal design: Version 2.0. Raleigh, North Carolina NC: The Center for Universal Design.

[6] UNESCO Headquarters (2011). Consultative expert meeting report. Accessible ICTs and personalized learning for students with disabilities: a dialogue among educators, industry, government and civil society.

[7] Newell, A.F. and Gregor, P. (2000). User sensitive inclusive design: in search of a new paradigm. In Proceedings of CUU 2000 First ACM Conference on Universal Usability, November 16-17, 2000 (Arlington, VA: ACM Inc.), 39-44.

[8] NieLSEN, J. (2003) Alternative interfaces for accessibility. Nielsen Norman Group. Available in: http://www.nngroup.com/articles/alternative-interfacesfor-accessibility/ (accessing data: 27/04/2014)

[9] Kelly, B.; Nevile, L., Sloan, D., Fanou, S., Ellison, R. and Herrod, L. (2009) From Web accessibility to Web adaptability. Disability and Rehability: Assistive Technology 4(4): 212-226.

[10] Minon, R.; Moreno, L.; Abascal, J. (2013). A graphical tool to create user interface models for ubiquitous interaction satisfying accessibility requirements. Universal access in the information society 12(4): 427-439.

[11] Bertini, E, S. and Kimani, S. (2003). Mobile devices: opportunities for users with special needs. In Chittaro, L. [ed.], Human-Computer Interaction with Mobile Devices and Services, (Berlin, Germany: Springer Verlag), 486491.

[12] Upadhyay, N. (2006) M-Learning-A new paradigm in education. International Journal of Instructional Technology and Distance Learning 3(2): 31-34.

[13] JoneS, A. Issroff, K.; Scanlon, E.; Clough, G.; Andrew, P. and Blake, C. (2006). Using mobile devices for learning in informal settings: is it motivating? In Proceedings of IADIS International Conference on Mobile Learning, July 14-16, 2006 (Dublin: IADIS Press), 251-255.

[14] KOPER, R. and VAN Es, R. (2004). Modeling units of learning from a pedagogical perspective. In McGreal R. [ed.], Online education using learning objects, (London: RoutledgeFalmer), ch 3.
[15] SHULER, C. (2012). iLearn II: an analysis of the education category of the iTunes App Store. New York: The Joan Ganz Cooney Center at Sesame Workshop. Available at: http:// joanganzcooneycenter.org/Reports-33.html (accessing data: 27/04/2014)

[16] Naismith, L.; Lonsdale, P.; Vavoula, G. and Sharples, M (2005). Literature Review in Mobile and Learning. FuturelabSeries (Berkshire, FutureLab), Report 11.

[17] ISEA, Prospective analysis of the associated potential to Mobile (in Spanish) (2009).

[18] Knight, V. \& McKissick, B. R. (2013). A Review of Technology-Based Interventions to Teach Academic Skills to Students with Autism Spectrum Disorder. Journal of Autism and Development Disorders, 43, 2628-2648.

[19] Ploog, O., Scharf, A., Nelson, D. \& Brooks, P. (2013). Use of Computer-Assisted Technologies (CAT) to Enhance Social, Communicative, and Language Development in Children with Autism Spectrum Disorders. Journal of Autism and Development Disorders, 43, 301-322.

[20] Zurita, G. and Nussbaum, M. (2004) Computer supported collaborative learning using wirelessly interconnected handhelp computers. Computer \& Education 42: 289-314.

[21] Dos ReIs, J.C.; Bonacín, R., Martins, M.C (2009) Using multimedia in the mobile collaborative learning. In Mendez-Vilas, A.; Solano-Martin, A. and MesaGoNZÁLEZ, J. [ed.], Research, Reflections and Innovations in Integrating ICT in Education, 2:869-873.

[22] Pownell, D. and BAiley, G. (2000). Handheld computing for educational leaders: A tool for organizing or empowerment. Leading \& Learning with Technology, 27(8): 1-8.

[23] FERnÁNDEZ, Á.; Rodriguez-Fortiz, M.J,; RodriguezAlmendros M.L; Martínez-Segura, M.J. (2012) Mobile learning technology based on iOS devices to support students with special education needs. Computers \& Education 61:77-90.

[24] Rodríguez-FóRtiz, M. J.; Villamía, B.; Cabrera-Cuevas, M.; Rodriguez-Almendros, M.L; Ruiz-López, T.; Rodríguez-Domínguez, C. Burgos-Pulido' M.A.; GarridoJimenez, I.; Martos-Perez, J. (2013) Enhancing the perceptive and cognitive visual processes in lowfunctioning autism: SIGUEME (FOLLOW-ME). In Proceedings of $X$ International Congress Autism Europe. Budapest, Hungary, on September 26-28, 2013. 